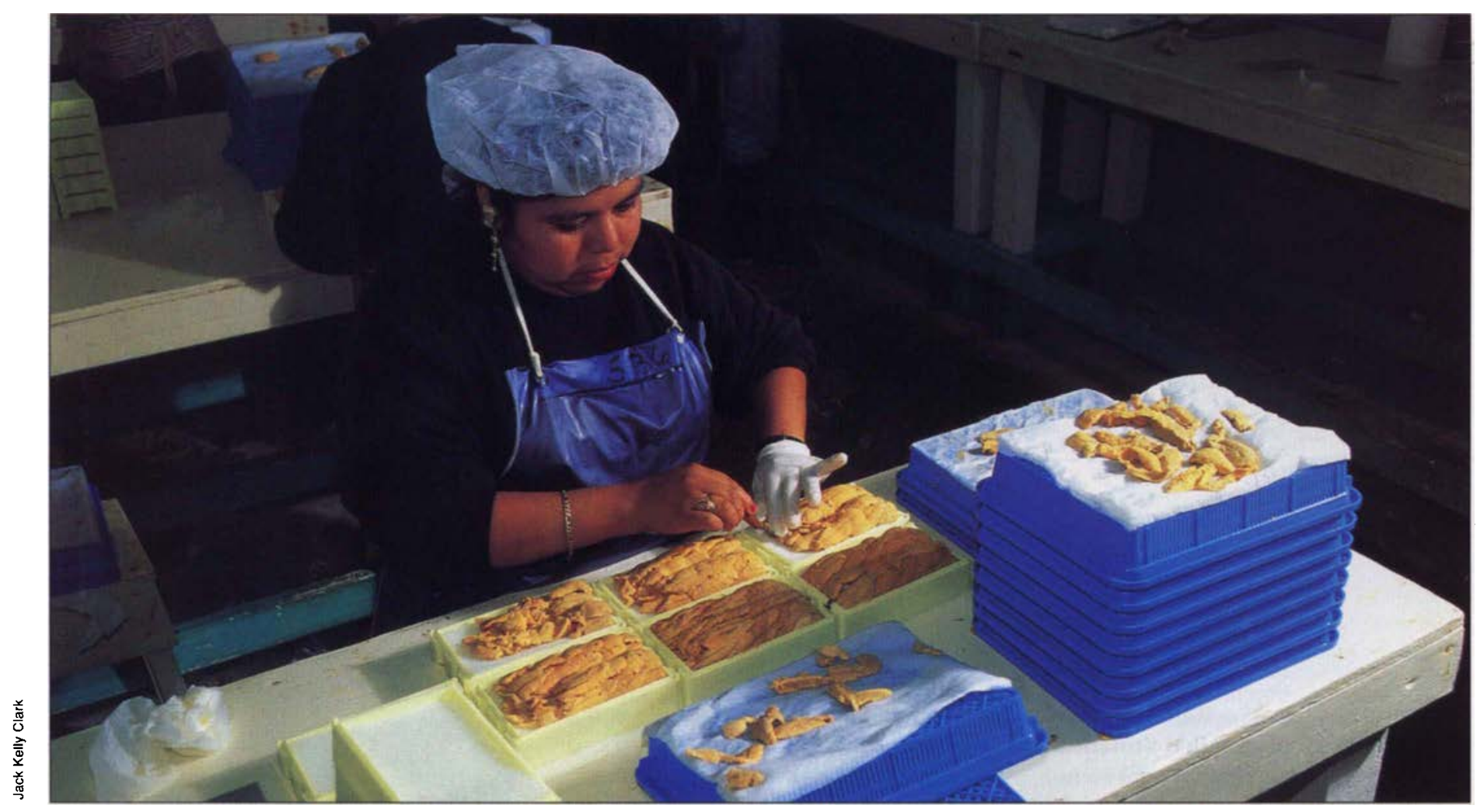

\title{
Monitoring and proper handling ensure seafood safety
}

\author{
Robert J. Price \ Pamela D. Tom
}

\begin{abstract}
Addressing seafood safety concerns through research and technology transfer is a major objec-
\end{abstract} tive of the California Sea Grant Extension Program. Currently a major emphasis of the Sea Grant Extension Program is educating the seafood industry about the Hazard Analysis and Critical Control Point (HACCP) system. Proper cooking destroys viruses, bacteria and parasites that can contaminate seafood. However, seafood may also contain natural toxins that are not destroyed by heat, such as the scombroid toxin formed by histamines in spoiled fresh albacore and other tunalike species. This paper provides an overview of seafood-borne illness; naturally occurring toxins in seafood; Sea Grant Extension efforts to assist the industry in complying with a new federal seafood safety regulation; and ongoing seafood safety projects.
Ceafoods are among the safest foods $\checkmark$ we eat. They were responsible for less than $5 \%$ of the reported cases of foodborne illness from 1973 to 1987 (Bean and Griffin 1990). Despite this record, seafood safety remains an issue that concerns many consumers, as well as regulatory agencies. Seafood consumption in the United States has risen steadily in recent decades, with annual per capita consumption now approximately $50 \%$ higher than it was 30 years ago. In addition, consumers today have a much larger selection of fish and shellfish to choose from than ever before.

Fortunately, the most popular varieties of seafood - such as shrimp, salmon and canned tuna - pose little risk of illness. The vast majority of cases of seafood-borne illness result from the consumption of raw or undercooked fish. Raw molluscan shellfish, in particular, accounts for more than $88 \%$ of seafood-borne illness cases in the United States (FDA 1995a) (see page 52).
Although outbreaks of seafoodborne illnesses occasionally occur in California, almost all are caused by seafood imported into the state: Raw oysters harvested in the Gulf of Mexico, for example, were responsible for five deaths in California in 1996.

Proper cooking destroys viruses, bacteria and parasites that can contaminate seafood. However, seafood may also contain natural toxins that are not destroyed by heat. Monitoring programs and proper handling procedures both play important roles in protecting consumers from these toxins.

\section{Seafood hazard control}

The California Sea Grant Extension Program supports research and extension activities aimed at helping fishers, processors and dealers to ensure the safety of the seafoods they deliver to consumers. Currently a major emphasis of the Sea Grant Extension Program is educating the seafood industry about the Hazard Analysis and Critical Control Point (HACCP) system. 


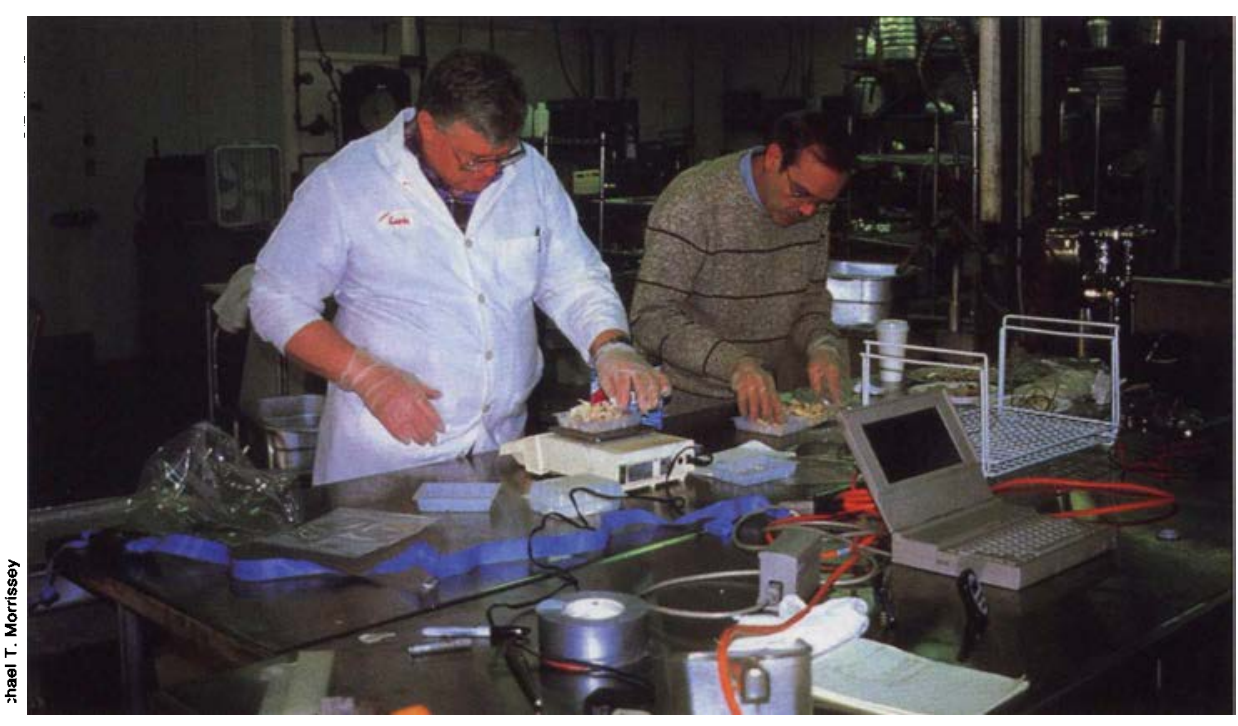

A Sea Grant Extension Food Technologist Bob Price (right) studied pasteurization technology for Dungeness crab, aimed at a new vacuum-packed product with a shelf life of 6 months. Longer shelf-life will help even out the supply of this highly cyclical product.

Seafoods cause less than $5 \%$ of the reported cases of foodborne illness. Monitoring programs and proper handling procedures play important roles in protecting seafood consumers. At Sonoma Offshore Products in Santa Rosa, a worker meticulously packs sea urchin roe or "uni" for shipment to Japan.

HACCP was originally developed to ensure the production of safe foods for the U.S. space program. The Food and Drug Administration (FDA) has issued new regulations that require seafood processors and importers to implement HACCP plans by December 1997.

As part of a continuing effort to improve seafood safety, Sea Grant Cooperative Extension seafood specialists (including the author, Robert Price, and experts from Alaska, Florida, Louisiana, North Carolina, Oregon and Virginia) joined with state and federal regulatory agencies and industry associations to form a national Seafood HACCP Alliance for Education and Training. The overall goal of the alliance is to assist the seafood industry in implementing HACCP food safety programs for seafood processors and importers.

$\mathrm{HACCP}$ is a preventive system of food safety control rather than a reactive one. In traditional food processing, processors relied on plant inspections and product testing to identify and control potential food safety hazards. By using the HACCP approach, seafood processors can target potential hazards before processing begins and set up methods to control them. These controls are monitored to ensure that they are working properly and that safe foods are being produced.
The Alliance Steering Committee developed a seafood HACCP training manual and a 3-day HACCP training course. With assistance from Sea Grant Cooperative Extension programs in other states, we trained more than 380 seafood HACCP trainers during 15 "train the trainer" courses held throughout the United States. HACCP Alliance members and the new trainers are currently teaching regulatory agency personnel and seafood industry workers how to develop HACCP food safety programs. This is a unique training program because regulatory personnel and members of the seafood industry are being trained simultaneously.

\section{Scombroid poisoning prevention}

In addition to HACCP education and training, our research and extension efforts in the areas of seafood safety and technology have focused on the prevention of histamine formation due to spoilage of certain types of fish. Histamine poisoning, also known as scombroid poisoning, is caused by high concentrations of histamine that form in fresh albacore and other tunalike species if they are not kept cool enough. The scombroid toxin is heat stable and is not eliminated by cooking or canning.

Fish that may produce scombroid toxin include mahi-mahi, tuna, amber- jack and mackerel. The flesh of these species contains relatively large amounts of the amino acid histidine. Certain spoilage bacteria that can grow on the fish after they die produce enzymes that convert histidine to histamine. Histamine poisoning symptoms usually begin within 4 hours after consuming contaminated fish. Common symptoms include a metallic, sharp or peppery taste in the mouth; nausea, vomiting, abdominal cramps and diarrhea; swelling and flushing of the face; hives; headache; dizziness; heart palpitations; rapid and weak pulse; thirst; and difficulty breathing.

There were 202 outbreaks consisting of 1,216 reported cases of scombroid poisoning in the United States from 1973 through 1987 (Bean and Griffin 1990). That represents an average of 13 outbreaks and 81 reported cases per year. Based on these data, the FDA estimates 8,000 cases per year (FDA 1995a).

Temperature control of fish catch is key to preventing histamine formation. Cooling albacore quickly after capture on fishing vessels is essential to slowing bacterial growth and histamine formation. Albacore and other tunas are unusual in that they maintain body temperatures as much as $6^{\circ}$ to $12^{\circ} \mathrm{F}$ higher than the surrounding water temperature (Van Oosten 1957). Further increases in an albacore's body temperature can occur as a result of its struggles during capture, resulting in

continued on p. 53

The Food and Drug Administration has told seafood processors that they must implement a new system for preventing seafood safety problems by December 1997 . The system is called HACCP (pronounced "hassip"), which stands for Hazard Analysis and Critical Control Points. To assist seafood processors and importers in implementing HACCP food safety programs, Dr. Price and other Sea Grant Extension seafood specialists nationwide joined with regulators and industry members to form the Seafood HACCP Alliance for Education and Training. The alliance has pub lished guidelines, listed under

"References." $-E d$. 


\section{continued from p. 51}

flesh temperatures as high as $92^{\circ} \mathrm{F}$ in albacore landed on a commercial fishing vessel. Fish held at $90^{\circ} \mathrm{F}$ can become toxic within 6 hours, whereas histamine production slows dramatically at temperatures below $40^{\circ} \mathrm{F}$.

Our research revealed that albacore tuna does not form significant amounts of histamine when properly handled at sea (Price et al. 1991). Histamine forms very slowly at $32^{\circ} \mathrm{F}$. Albacore chilled in slush ice (two parts ice to one part seawater) immediately after capture and stored in ice produced measurable amounts of histamine only after 27 days in storage, by which time spoilage was obvious. The results of this study were used by albacore fishermen to improve handling techniques and ensure a safe product for consumers.

\section{Ciguatera}

Whereas histamine forms as a result of bacterial growth during spoilage, many other naturally occurring toxins can accumulate in the flesh of shellfish and certain finfish before they are harvested or captured. In most cases, these toxins are formed by dinoflagellates or other phytoplankton.

Ciguatera poisoning is caused by a toxin that can accumulate in certain tropical and subtropical fish. Although it affects an estimated 1,600 people in the United States each year (FDA 1995a), making it one of the most common finfish-caused foodborne illnesses, ciguatera poisoning is rare in California.

Two outbreaks of ciguatera fish poisoning occurred in Southern California in 1992 and 1994, the first such incidents from fish landed in the state. The 1992 outbreak caused an epidemic of 25 cases; it was traced to red-tipped rock bass caught at Alijos Rocks, about 200 miles off the coast of Baja California. The 1994 outbreak affected about 20 people and was traced to a yellowtail also caught in the Alijos Rocks area. Most cases of ciguatera fish poisoning in the United States and its territories occur along the eastern coast from Florida to Vermont and in Hawaii, the U.S. Virgin Islands and Puerto Rico.
Ciguatoxin originates in a type of plankton associated with coral reefs, the dinoflagellate Gambierdiscus toxicus. The toxin passes from the plankton to plankton-feeding fish and invertebrates, then to predatory fish, becoming more concentrated with each step up the food chain. The toxin has been found in more than 400 species of fish associated with tropical and subtropical reefs. Marine fish commonly associated with ciguatera fish poisoning include large, predatory species such as the groupers, barracudas, snappers, jacks, mackerels and triggerfish. The occurrence of toxic fish is sporadic, and not all fish of a given species or from a given locality will be toxic.

Symptoms of ciguatera poisoning vary widely, but usually involve both gastrointestinal and neurological complaints that begin shortly after consumption of poisoned fish. These may include diarrhea, abdominal pain, nausea, vomiting, abnormal or impaired skin sensations, vertigo, lack of muscle coordination, reversal of hot and cold sensations, muscular pain and itching. Although ciguatera poisoning is occasionally fatal, most patients recover within several days. Some patients experience persistent neurological symptoms for 6 months or longer.

Although various bioassays have been developed to screen fish for toxicity, none are suitable for commercial use. Commercial fishermen have had to rely on local knowledge of safe harvest areas to avoid ciguatoxic fish. Recent studies have focused on the development of immunochemical testing techniques, resulting in laboratory assays and a low-cost, simplified field test for ciguatoxin that is currently being evaluated in international trials (Ward and Hart 1996).

\section{Shellfish toxins}

Four distinct types of marine biotoxins that can poison humans are found in molluscan shellfish (oysters,

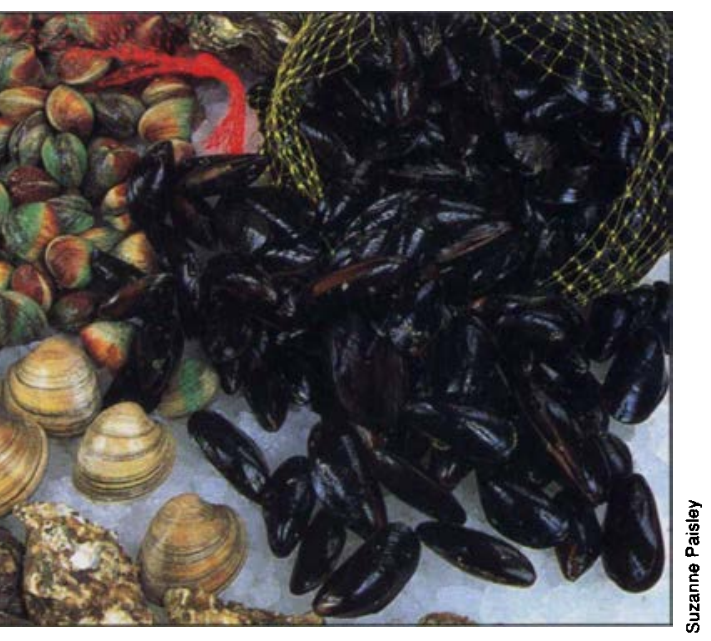

Marine biotoxins that can poison humans can be found in molluscan shellfish including oysters, mussels, clams and scallops. The California Department of Health Services licenses commercial shellfish harvesters and tests and certifies their shellfish to be safe.

mussels, clams and scallops) in the United States. In all states where shellfish are harvested, state agencies monitor shellfish waters, or each batch of commercially harvested shellfish, for toxins and regulate commercial and recreational harvesting to prevent human consumption of toxic shellfish (see page 54). The California Department of Health Services (CDHS) licenses commercial shellfish harvesters and tests and certifies their shellfish to be safe. CDHS also places quarantines on sport harvesting during periods when unsafe levels of toxins occur: The agency monitors marine toxins in sport and commercial seafoods year-round.

Paralytic shellfish poisoning (PSP) is caused by toxins (saxitoxins) produced by many different species of marine algae. In California, an annual quarantine on sport harvesting of mussels extends from May 1 through Oct. 31, the period when mussels are most likely to accumulate PSP toxin. Almost all (over 99\%) of the PSP cases in California have occurred during this quarantine period.

PSP symptoms begin with tingling and numbness of the lips, tongue and fingertips, starting within a few minutes to a few hours after eating toxic shellfish. Later symptoms include lack of balance, lack of muscle coordination, slurred speech and difficulty swallowing. Complete paralysis and death may occur in severe cases. 
Amnesic shellfish poisoning (ASP) is caused by domoic acid produced by certain species of diatoms. Although domoic acid has been detected in shellfish in California, no cases of ASP have been reported in the state.

Other human illnesses caused by toxins in shellfish include diarrhetic shellfish poisoning (DSP), caused by okadaic acid and its derivatives produced by algae in the genera Dinophysis and Prorocentrum, and neurotoxic shellfish poisoning (NSP), caused by brevetoxins produced by Gymnodinium breve.

CDHS provides current updates on marine toxin activity in California, which can be accessed by telephone (510/540-2605 or 800/553-4133).

\section{Seafood safety compendium}

As part of our Seafood HACCP Alliance activities, we have developed the Compendium of Fish and Fishery Product Processing Methods, Hazards and Controls. The Compendium includes sections on seafood processes and controls, as well as biological, chemical and physical hazards and controls. It provides the seafood industry with information on documented seafood process parameters, federal guidelines and tolerances for seafood contaminants, bacterial growth parameters and recommended hazard control options. The Compendium will assist the seafood industry in developing effective HACCP plans by providing scientific information on food-safety hazards and controls. It is available for viewing or downloading on the Internet (http://www-seafood. ucdavis.edu/haccp/compendium/ compend.htm). Research results on histamine prevention and control, as well as other hazards and controls, will be added as new information is published.

In projects funded by the U.S. Department of Agriculture, and in cooperation with Sea Grant programs in North Carolina and Alaska, we have developed HACCP food safety guides for delicatessens and for the musselprocessing industry (Price et al. 1993; Price et al. 1995). A publication entitled Ensuring Food Safety - The HACCP Way was cited by the

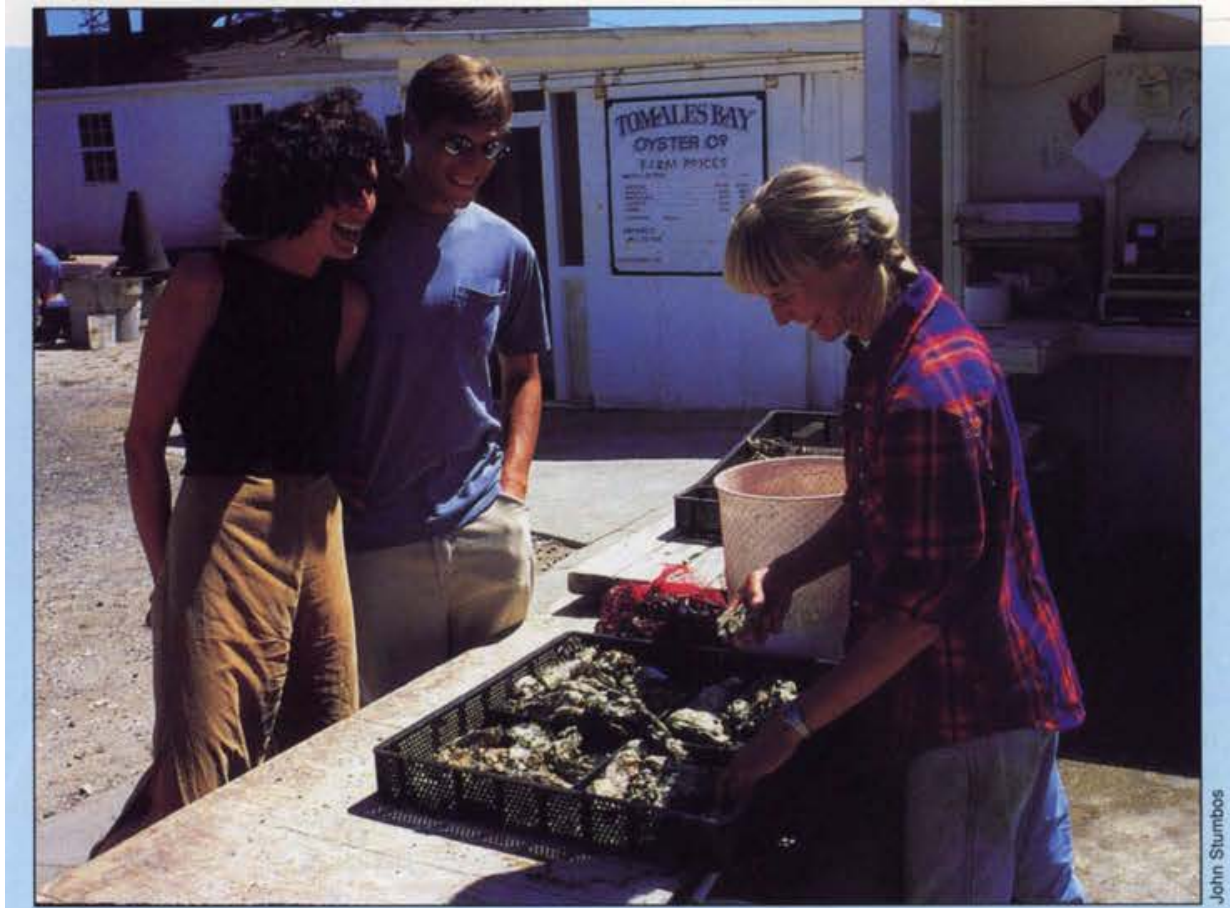

The oyster culture industry has been a part of Marin County's agriculture since the turn of the century.

\title{
Aquatic and land-based agriculture share vital water resources
}

\author{
Paul G. Olin
}

Tomales Bay and the surrounding watersheds provide a window into efforts to improve coastal water quality by controlling nonpoint-source pollution. A variety of programs are helping to maintain viable livestock and dairy operations in coastal Marin County, while keeping water quality high enough to support the oyster culture industry that has been a part of the region's agriculture since the turn of the century.

Nonpoint-source pollution - ranging from agricultural runoff to chemical pollutants washed into storm drains from urban areas - is a major factor in the deterioration of coastal water quality throughout the developed world. Shellfish are especially vulnerable to coastal water pollution because they filter their food from the water and can thereby concentrate pollutants in their tissues. In Tomales Bay, bacteria carried in runoff from livestock operations have caused interruptions in shellfish harvests immediately following heavy winter rains.

Oysters are frequently eaten raw on the half-shell, making contamination with bacterial or viral pathogens a serious concern. The Food and Drug Administration, in conjunction with individual states, operates the National Shellfish Sanitation Program to ensure that oysters and the waters they are grown in are free of harmful bacteria levels. In California, oyster-growing waters are monitored by the State Department of Health Services for total and fecal coliform bacteria, which may indicate potential sewage contamination. Coliform bacteria exist in the intestinal tracts of warm-blooded animals and birds, and are commonly found in soil and water. Fecal coliforms are common in the digestive tracts of warm-blooded animals and birds. 


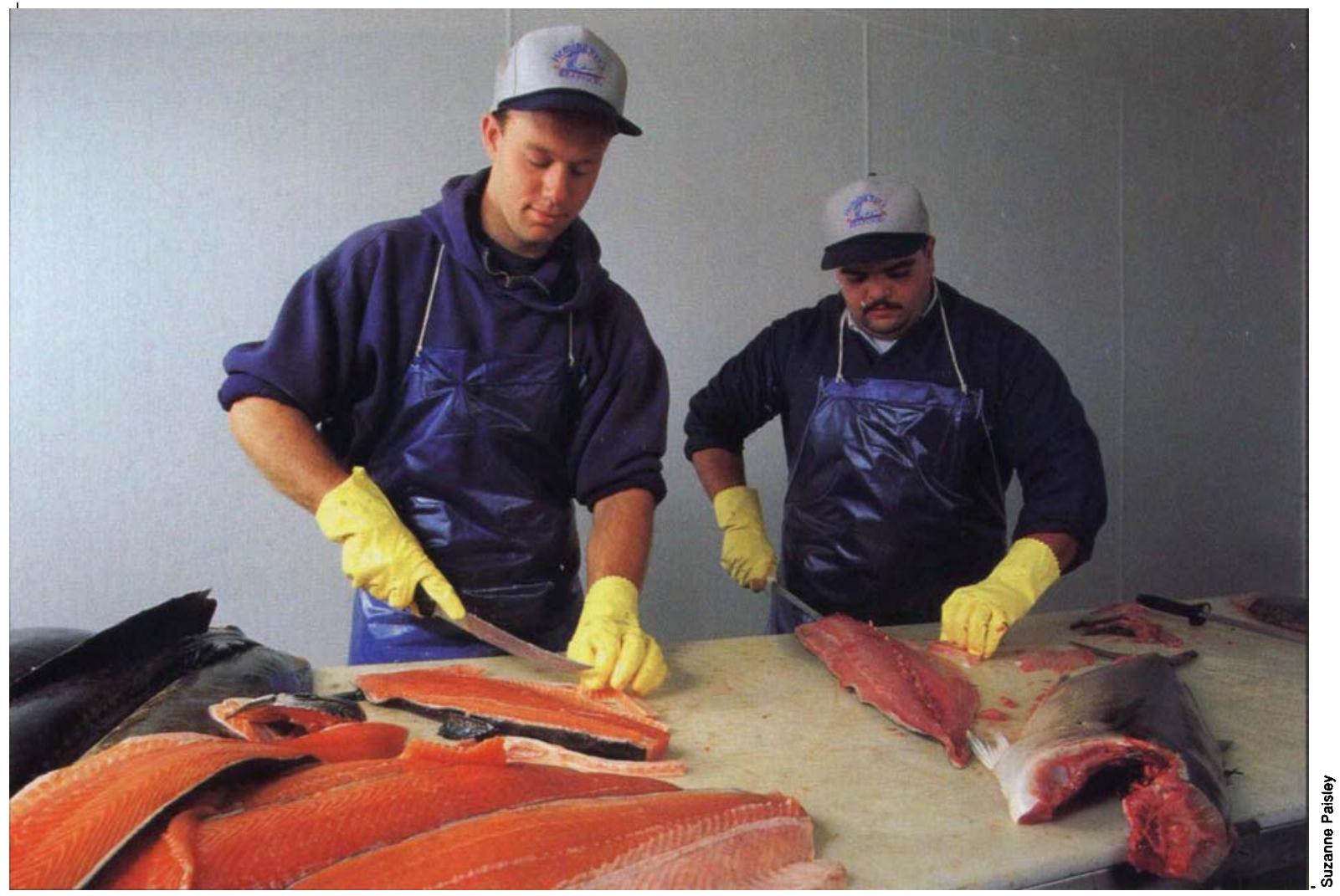

Proper handling and preparation of raw fish greatly reduce consumers' chances of getting sick. Patrick Harrington and Andrew Margherita of Hemingway's Seafood in Sacramento prepare salmon.

\section{continued from p. 54}

Secretary of Agriculture as an example of "an excellent product from a highly successful USDA-funded project." Published by the UC's Sea Grant College Program, this guide was translated into Spanish, and both the English and Spanish versions have been widely requested throughout the United States.

Our ongoing seafood safety and histamine-related projects include a review of the usefulness of rapid test kits for pathogenic microorganisms and marine toxins in seafood HACCP programs (in cooperation with the National Fisheries Institute); research with Oregon State Sea Grant on histamine formation and control in albacore tuna; and an evaluation, in cooperation with Florida Sea Grant, of rapid histamine test kits.
R.J. Price is Food Technology Specialist and P.D. Tom is Program Representative, Department of Food Science and Technology, UC Davis.

\section{References:}

Bean NH, Griffin PM. 1990. Foodborne disease outbreaks in the United States, 19731987: Pathogens, vehicles, and trends. J Food Protect 53(9):804-17.

FDA. 1995a. Procedures for the safe and sanitary processing and importing of fish and fishery products; Final rule. Fed Reg 60(242):65096-202

FDA. 1995b. Food Code. U.S. Department of Health and Human Services, Public Health Service, Food and Drug Administration, Washington, DC. $189 \mathrm{p}$.

Kalamaki M, Price RJ, Fung DYC. 1997. Rapid methods for identifying seafood microbial pathogens and toxins. J Rapid Meth Automat in Microbiol. 5:87-137.
Price RJ, Kramer DE, Tom PD. 1996. Processing mussels - the HACCP way. UCSGEP 96-2. California Sea Grant College Program, UC Davis (CA)

Price RJ, Melvin EF, Bell JW. 1991. Postmortem changes in chilled round, bled and dressed albacore. J Food Sci 56(2):318-21.

Price RJ, Tom PD, Stevenson KE. 1993. Ensuring food safety - the HACCP way. California Sea Grant College Program, University of California, La Jolla (CA)

Price RJ, Tom PD, Stevenson KE. 1995. Como asegurar la calidad de los alimentos siguiendo el sistema HACCP. (Traducción al español: Maria V. Chang-Lee y Myriam GrajalesHall.) California Sea Grant College Program, University of California, La Jolla (CA).

Van Oosten J. 1957. The skin and scales. In: Brown ME (ed). The Physiology of Fishes, Vol. I. New York: Academic. p 207

Ward D, Hart K. 1996. Hazards found in seafood, appendix III. In HACCP: Hazard Analysis and Critical Control Point Training Curriculum. Raleigh (NC). North Carolina Sea Grant, North Carolina State University, p. 13-180.

\section{CALIFORNIA AGRICULTURE ASSOCIATE EDITORS}

Animal, Avian, Aquaculture

\section{\& Veterinary Sciences}

Christopher M. Dewees

Kathryn Radke

Bennie I. Osburn

Barbara A. Reed

Economics \& Public Policy

Richard A. Howitt

Alvin Sokolow

Food \& Nutrition

Barbara Schneeman

Eunice Williamson
Human \& Community Development

Linda M. Manton

Karen P. Varcoe

Land, Air \& Water Sclences

Garrison Sposito

Henry J. Vaux, Jr.

Natural Resources

Barbara H. Allen-Diaz

Daniel W. Anderson

Richard B. Standiford
Pest Management

Edward G. Platzer

Joseph G. Hancock, Jr. Michael K. Rust

Plant Sciences

Jodie S. Holt

Lee F. Jackson

G. Steven Sibbet http://danr.ucop.edu/calag/

CALAG@ucop.edu

$\mathrm{PH}$ : (510) 987-0044

FAX: (510) 465-2659 